\title{
Precis: Enactivist Interventions
}

\author{
Shaun Gallagher ${ }^{1,2}$
}

Published online: 1 January 2019

(c) Springer Nature B.V. 2019

In Enactivist Interventions I begin by asking, "Is cognition in the head or in the world, or in some mix of brainy and worldly processes?" (Gallagher 2017, 1). The answer that I develop is that cognition involves an integration of brainy and worldly processes. Each chapter aims to address an important topic or set of concepts that contributes to contemporary discussions in philosophy of mind and cognitive science.

In the introduction I start by clarifying the positions that I am criticizing-not just classic cognitivism, but also the more recently developed view that Alsmith and de Vignemont (2012) call 'weak' embodied cognition. This is the idea that cognition is embodied only in the sense that it involves body-formatted representations in the brain. I also introduce the position that I am defending-enactivism. In the other chapters I attempt to explain what I take to be the central principles of enactivism. I list seven of them (a list that is not meant to be exhaustive or completely systematic). First, cognition is not simply a brain event. It emerges from processes distributed across brain-body-environment. Second, the world (meaning, intentionality) is not pre-given but is enacted by cognition, action, and social interaction. Third, our understanding of cognitive processes has to be in view of their role in worldly contexts where they acquire meaning rather than as a representational mapping or replicated internal model of the world. Fourth, enactivist approaches have strong links to dynamical systems theory, and they emphasize the relevance of dynamical coupling and coordination across brainbody-environment. Fifth, cognitive systems are extended, intersubjective, and socially situated, but the concept of extension is not equivalent to the functionalist

Shaun Gallagher

s.gallagher@memphis.edu

1 University of Memphis, Memphis, USA

2 Faculty of Law, Humanities and the Arts, University of Wollongong, Wollongong, Australia 
extended mind. Sixth, higher-order cognitive functions, such as deliberation, reflective thinking, and imagination, are exercises of skillful know-how and are closely coupled with situated and embodied actions. And seventh, such complex cognitive functions are grounded not only in sensorimotor coordination, but also in affective and autonomic aspects of the full body.

I provide a broad historical background (showing how enactivism is influenced or prefigured by pragmatism and phenomenology) and I situate it in the contemporary context of embodied cognition. Enactivism as one of a number of approaches to embodied cognition emphasizes agency and social interaction. In such actionoriented contexts one central question is how to think of intentionality. This is where enactivism capitalizes on both its phenomenological and pragmatic roots and shows how to move away from neo-Cartesian and neo-behaviorist conceptions of intentionality. In this regard a neopragmatist view of intentionality works best to capture the contextualized, action-oriented nature of cognition. I argue that on this conception of intentionality the opposition between enactivism and extended mind approaches can be resolved in a way that deflects the major internalist criticisms concerning the contrast between causality and constitution, and the "mark of the mental" understood, for example, as intrinsic or non-derived intentionality. Enactive intentionality is not conceived in terms of representation, but in terms of action-oriented responses to worldly events and to other agents. As non-derived intentionality, I argue, it is not equivalent to internal representational processes, but to what phenomenologists call operative or bodily intentionality.

The issue of representation is a central one that delineates classic cognitivist, and even more progressive accounts of distributed or extended cognition from enactivist approaches. In a chapter that focuses on the question of whether we require the concept of representation in an account of action, I argue that if we start with standard definitions of representation in philosophy of mind, then perception and action-related processes are non-representational. I consider various concepts of action-oriented representations (found in Clark 1997; Wheeler 2005; Rowlands 2006, 2012, and others) and attempt to show why these processes do not fit the definition of representation.

How, then, does the brain work if it is not generating internal mental representations of the world? I contrast predictive processing accounts, which take perception to be an inferential process, with the enactivist view that the brain, as part of the body-environment system (not only regulating body, but regulated by the body and its affective processes), is, as Jesse Prinz puts it, 'set up to be set off ' (2004, 55). Set up by evolution and developmental processes, and by prior experience and plastic changes; set off in dynamical response patterns by the agent's worldly engagements. On this view the brain works as an integral part of the organism which responds dynamically to environmental changes. If, in predictive processing accounts, the notion of 'active inference' comes closest to this enactivist view, I suggest, we need to think of that process as one where the embodied agent actively engages in the world rather than as one where an inference-making brain generates action simply for purposes of predicting or sampling an unknown environment. 
With respect to action I argue that there is a philosophically significant difference between concepts of free will and motor control. This is a difference that gets obscured both in neuroscientific experiments (such as the Libet experiments) and in standard philosophical discussions that conceive of free will in terms of mental causation where mental states are understood to cause bodily movement. Rather than getting snagged on this standard account of free will which focuses the issue on bodily movement rather than action in the world, it may be better to talk about autonomy. Here it is better to conceive of autonomy as relational, rather than as a pre-established character of human nature. In this respect an agent's degree of autonomy can be understood in terms of the quality and quantity of affordances available to her, and is best conceived on a narrative timescale involving intention formation and action in social contexts, instead of in terms of the elementary timescale (milliseconds) of neuronal processes.

Although enactivism has often been framed as a theory of sensory-motor contingencies (e.g., O'Regan and Noë 2001), I argue that this is an overly narrow conception even when it comes to perception. Here, like a number of recent enactivist accounts of affect (e.g., Colombetti 2013), I emphasize the role played by very basic bodily affects (including phenomena such as hunger and fatigue, as well as moods and emotions). Perception, and cognition more generally, are shaped by affect, so that in perceiving action possibilities we are not only governed by the "I can" of sensory-motor contingencies (i.e., seeing things in terms of what we can do with them or how we can act in regard to them), but also by feelings of whether I even want to, or have enough energy to do something or act in some way. In this regard, we should not think of affect as merely a matter of bodily processes (although that's an important part of the story), we should think of affect as socially situated and as modulated by our intersubjective relations.

In these considerations about affect and intersubjectivity, my aim is to flesh out a richer conception of embodied cognition. In this regard I also point to some evolutionary considerations about upright posture and a concept of embodied rationality. The notion that we engage with the world and with others in an affordance-based fashion is closely tied to our bodily form.

A lot of enactivist analysis is focused on perception and action and what Hutto and Myin (2013) call 'basic minds'. One frequent criticism is that enactivism can't account for the more complex cognitive processes of memory, imagination, counterfactual thinking or reflective problem solving. In the final chapter of Enactivist Interventions I take up this problem, which is sometimes called the problem of 'scaling up'. The question is whether an enactivist approach can explain such complex cognitive processes. To gain some traction on this issue I rehearse the recent debate between Hubert Dreyfus and John McDowell concerning the nature of the mind. I suggest that we can split the difference between Dreyfus (who emphasizes embodied skills and coping) and McDowell (who focuses on concepts and the space of reasons). I argue that reflection and conceptually rich cognitive operations involve a specialized affordance space that is nonetheless continuous with embodied coping. Something like this is suggested by Ryle's analysis of imagination in terms of pretense, as well as by Sartre's suggestion that imagination is grounded on embodied processes. Finally, I consider an account of mathematical 
reasoning rooted in approaches that consider the importance of gesture, bodily performances, everyday pragmatic dealings with the world, and specific types of cultural practices. On such analyses, it's rare that we do the math in our heads; the more common practice is to do it by way of skillful engagements with the world in ways that allow us to treat conceptual systems as systems of affordances for solving problems. Although I cannot claim to have given anything near a complete or perhaps even convincing enactivist account of these more complex forms of cognition, my hope is that by building on the work of a number of other theorists I've provided some suggestive sketches that indicate the direction that a fuller enactivist account might take.

\section{References}

Alsmith, A. J. T., \& de Vignemont, F. (2012). Embodying the mind and representing the body. Review of Philosophy and Psychology, 3(1), 1-13.

Clark, A. (1997). Being there: Putting brain, body, and world together again. Cambridge, MA: MIT Press.

Colombetti, G. (2013). The feeling body: Affective science meets the enactive mind. Cambridge, MA: MIT Press.

Gallagher, S. (2017). Enactivist interventions: Rethinking the mind. Oxford: Oxford University Press.

Hutto, D., \& Myin, E. (2013). Radicalizing enactivism: Basic minds without content. Cambridge, MA: MIT Press.

O’Regan, J. K., \& Noë, A. (2001). A sensorimotor account of vision and visual consciousness. Behavioral and Brain Sciences, 24(5), 939-973.

Prinz, J. (2004). Gut reactions: A perceptual theory of emotion. New York: Oxford University Press.

Rowlands, M. (2006). Body language. Cambridge, MA: MIT Press.

Rowlands, M. (2012). Representing without representations. AVANT, 3(1), 133-144.

Wheeler, M. (2005). Reconstructing the cognitive world: The next step. Cambridge, MA: MIT Press.

Publisher's Note Springer Nature remains neutral with regard to jurisdictional claims in published maps and institutional affiliations. 